\section{Civil Society and Social Capital in Japan}

\author{
Yutaka Tsujinaka
}

School of Political Science and Economics, Tokai

University, Hiratsuka, Japan

University of Tsukuba, Tsukuba, Japan

\section{Definition}

Civil society in Japan is characterized as having a wide variety of organizations. It has a long history and abundant social capital. At the same time, in the course of Japan's modernization accomplished through cooperation between public and private sectors, these organizations remained somewhat invisible. Nonprofit organizations were subject to supervision and protection by the competent government agencies. Public interest (service) corporations flourished as the form of economic and professional nonprofit organizations that contributed to Japan's industrialization. At the same time, thousands of voluntary grassroots organizations, unable to obtain a corporate status, continued their activities. However, the 1998 NPO Law and the 2008 (enacted 2006, enforcement 2008) Public-Interest Corporations System reforms led to the creation of more than a hundred thousand independent, private voluntary organizations. Grassroots civil society organizations including traditional neighborhood associations and newly created nonprofit corporations have become more visible compared to the era when they were outside the old scheme. Nonetheless, this new sector, mostly engaged in public service activities at the local level, remained financially vulnerable. Another concern among all types of civil society organizations is declining membership. To deal with the aging society, recurrent natural disasters, and financial difficulties, local governments and political parties have higher expectations regarding the roles played by civil society, while Japan's conservative government is still reluctant to give full legitimacy to the concept of civil society.

\section{Introduction}

The term "civil society" (Shimin shakai) and the related words such as "NGO" (nongovernmental organization) and "NPO" (nonprofit organization), generally came into common use in Japanese mass media since the 1990s, particularly after the Great Hanshin-Awaji Earthquake in 1995 (Tsujinaka et al. 2007). However, the substance of civil society (indicating here simply social organizations independent from the modern state) has a longer history in Japan, while the nature of such organizations has been problematic in academia (Garon 2003; Pekkanen 2003; Tsujinaka 2002b). Although this may be similar to the situation in other non-Western or Asian countries, the context in which these phrases have been used differs from that of Western societies in daily life as 
well as academia (Alagappa 2004). Even today, the term "civil society" is not frequently used in Japan. For example, according to the National Diet Record Database, the term "civil society" appeared 872 times between 1945 and 2019. Of the 872 , the term was used 570 times between 1999 and 2019.

According to Fukuda (2006) and Najita (2009), there is a great deal of historical evidence concerning associational development in premodern Japan. After the Meiji Restoration in 1868, what we consider modern associations formed rapidly. It is impossible to understand Japan's civil society experience without taking into consideration the organizational experiences and the accumulation of social capital that took place before Japan's modern period.

Since the modern revolution, Japan experienced several waves of democratization. First, during "the movement for freedom and people's civil rights (Jiyu-minken)" from the 1870s into the 1880 s, over 2000 civic associations were recorded as being formed. Furthermore, together with the start of Japan's constitutional government in 1889 , increases in land taxes prompted close to 4000 petitions in a certain year. Various groups such as agricultural associations, chambers of commerce, business associations, and industrial associations formed rapidly. Particularly during the development of party politics from 1918 to 1937, the wave of association establishment included labor unions and social movements (Tsujinaka 1988; Garon 2003). However, by the end of the 1930s, all of the associations were either absorbed within war mobilization efforts or coerced and ultimately realigned into the state corporatist structure (Pempel and Tsunekawa 1979). This meticulous systematization throughout almost all association sectors would directly affect Japan's civil society after World War II.

After the war, under the Occupation, the Japanese New Constitution was enacted in 1947, and societies and petitions were liberalized and became fully legitimated. Alongside the democratic constitution, various new laws were enacted relating to associations, and Japan's civil society was virtually reborn. Japan's defeat and the postwar reforms caused remarkable discontinuation in civil society. A particularly illustrative example is that of labor unions which recorded an unprecedented high unionization rate of $56 \%$ in 1949 , despite the fact that there were no unions under the war system (Tsujinaka 1988; Kage 2010). Similarly striking figures were also seen with cooperative associations, as consumer groups and citizens' organizations such as the Japan Housewives' Association came into being. After the end of the Occupation in 1952, further legislation was enacted, particularly with regard to industrial associations, providing the initial structure for Japan's civil society that would continue through Japan's high-growth period of the 1960s and into the early 1970s.

Unlike the above understanding, a crossnational comparative survey of civil society from the perspective of the nonprofit sector conducted in over 30 countries by the Johns Hopkins Comparative Nonprofit Sector Project (Salamon et al. 2004) ranked Japan in the middle between Western developed nations and non-Western developing nations. When considering "civil society" as an idealized alternative of Western societies, the Western-type advocacy groups such as NGOs and NPOs have garnered a certain amount of attention, and it has been pointed out that Japan's civil society is comparatively weak and underdeveloped. If the term "social capital" is used to refer to relationships between fellow human beings, public and private networks, trust, and reciprocity norms, then it can be argued that Japan's economic-oriented society, with its traditionally broad and multiple grassroots structure, corporations and industry, demonstrates evidence of a wealth of social capital (Fukuyama 1995; Inoguchi 2002). In fact, there has been a great deal of debate regarding the nature of Japan's civil society as being "rich" in social capital yet "poor" in terms of civic-advocacy (Pekkanen 2006; Schwartz and Pharr 2003).

Such contrasts were also apparent when the 2011 Great East Japan Earthquake happened. At that time, citizens and organizations worked closely to save lives and rebuild the disasterstricken communities, showing dense social capital in the society. On the other hand, while the majority of Japanese people agreed on the need to 
reduce dependence on nuclear energy, advocating such an idea remained weak even after the earthquake (as it was before) (Tsujinaka and Inatsugu 2018).

As will be described later, there appeared a rich substance, that is, a sufficient number of groups and vibrant activities of civil society in Japan since at least the 1970s. Yet, why has the concept of "civil society" not acquired legitimacy even after the 1990s? These puzzles provide clues to understanding Japan's civil society and social capital. There is a clear need for approaches to civil society with a broad perspective in order to answer these problems (Tsujinaka et al. 2007).

\section{Civil Society}

It is generally thought that the development of civil society in many Western countries has accompanied the appearance and features of modern societies and modern states (Schwartz and Pharr 2003). Yet, in Japan, modern society and civil society were not considered to be corresponding. In fact, it was not until the $1990 \mathrm{~s}$ when the two concepts became equivalent. What enabled it to become a widespread phrase was the tragedy of the Great Hanshin-Awaji Earthquake in 1995 and the "volunteer revolution" that ensued.

Three reasons can be provided for the amount of time that it has taken for "civil society" to take root in Japan even under the postwar democratic constitution. First, for a long time, the phrases "citizens" and "civil society" held the implications of participation in urban areas. Until recently opposition political parties were mainly concentrated in such urban areas, and the concepts of "citizens" and "civil society" came to be associated with such opposition forces. For this reason, many conservative leaders still resist using these terms, even though the urban population exceeded $90 \%$ in 2010 .

Second, the long-standing "statist" bureaucratic regulations were another factor. Especially the Civil Code in 1896 and other laws have molded the arrangement of civil society since the Meiji era to the present and bureaucratic paternalistic culture toward civil society that has been influential even until recently (Pekkanen 2006; Garon 2003). The state's goals have revolved around modernization stances that have focused on bureaucracy-led "catching-up" processes (e.g., "rich nation and strong army" in the prewar era and "Income Doubling plan" in the 1960s).

Third, an additional criticism came from the left, pointing out that "citizens" (shimin), residents (jumin), and the populace (minshu) did not share the same "public" perspective. With a background of class consciousness, it was thought that there was a perceived bias toward urban residents, the educated class, and the socially aware middle class, leading to questions as to whether the working class and the general populace were being excluded. According to Yamaguchi (2004), there was also the further criticism from the left that residents' movements were contrapositive to citizens' movements.

By the start of the twenty-first century, however, there were few definitive ideological differences between the ruling conservative government and the opposition. During the process of the formation of the NPO Law (1998), ruling and opposition parties as well as labor and management were able to cross their existing boundaries to combine forces in establishing the law. Although the name of the NPO Law had changed from the proposed Citizen Activities Promotion Law to the Law to Promote Specified Nonprofit Activities, in the first section of the law, this law has assumed the character of a law "promoting sound development of specified non-profit activities carried out by citizens." Thus, in the aftermath of the Great Hanshin-Awaji Earthquake together with the burst of volunteer activity, expectations for civil society were quite high.

After the NPO Law was enacted, administrative reorganization took place in central and local governments. While central government consolidated its power in 2001, decentralization of authority to local governments and municipal mergers were also encouraged. Consequently, the number of local governments at the beginning of the twenty-first century had declined from 3229 to 1718 . Neoliberal reforms in Japan also affected the public interest corporation system, leading to changes in how government manages civil 
society. The 1896 Civil code was significantly revised in 2008. This led to the creation of incorporated associations and foundations without a bureaucratic competent authority system.

A bureaucratic competent authority system over civil society is a statist system where each central government ministry gives permission to relevant groups to register as a nonprofit organization and oversees their activities. Until 2008, this system covered essentially all social domains. After these reforms, more than a hundred thousand new organizations including incorporated NPOs and general incorporated associations and foundations were created. Those associations were no longer constrained by the bureaucratic competent authority system (Ushiro and Sakamoto 2019).

Although regulations of civil society have been generally relaxed, it is possible that civil society organizations could be affected by some part of any of 216 different corporation-related laws that continue to exist today. In the reform and even after, government intentionally and cleverly avoided using such terms like "civic," "civil," and "civil society," and instead used "people," "nation," "residents," and "non-profit activities."

\section{Social Capital}

Social capital is a concept that quickly attracted much attention in Japan, which has faced difficult social problems such as an advanced aging society and recurring natural disasters that other developed countries will also encounter in the twentyfirst century.

It should be emphasized first that social capital has two meanings in Japanese context. In Japan, social capital commonly refers to social overhead capital (or social common capital) in the media and daily conversations (Tsujinaka 2002a; Miyamoto 1976). Social overhead capital includes a road, a harbor, an airport, the railroad as industrial infrastructure facilities, a telegraphic communication telephone, a public housing, water and sewage, a city park, a hospital, the school, etc. The product of social overhead capital has more or less public goods nature. Therefore, they have the property that a sufficient supply is not necessarily guaranteed through the market mechanism.

However, another meaning spread to academia in the twenty-first century, just same as other advanced countries. That is, social capital as social or human relational capital. This basically overlaps the concept Putnam focused on, which entails trust, reciprocity, and social networks. It has been imported to Japan and developed since 1990s by many different applied researchers. The second point of emphasis is that this new concept, social capital as social relational capital, is a somewhat ambiguous concept that also has a wide range of meaning and usage, from micro to macro in different disciplines. This character is common with other advanced countries, as is its starting point in Putnam. The social capital has taken on a multifaceted character as a "variable" incorporating diverse social policy orientations and applications (Inoguchi 2002; Cabinet Office 2003; Inaba and Yoshino 2016; Ikeda 2019).

Third, systematic empirical research on civil society organizations, NPOs, the nonprofit sector, and NGOs continues to advance. This can be considered as part of the structural research that focuses on social capital (Tsujinaka and Yamauchi 2019).

Finally, in Japan, an empirical development of new social capital research based on Japanese reality has been deepened by a group led by Inaba (Inaba and Yoshino 2016). He has systematically supervised in editing six volumes series in the academic fields of statistics and social surveys, pedagogy, economics, management, civil society and political science, health and welfare, and sociology. In the micro approach, the intellectual contributions by Ikeda (2019) are also remarkable.

In dealing with recurring natural disasters (Aldrich 2012), such as the Great East Japan Earthquake in 2011, Kumamoto Earthquake in 2016, flood in Chugoku-Shikoku region in 2017, and new coronavirus problem in 2020, close cooperation among outstanding individuals, civil society organizations, and government clearly demonstrated the high accumulation of social capital in Japan. 


\section{Empirical Data}

There has been a wealth of statistics collected concerning the development of civil society spanning from 1950 to the present time (Tsujinaka 2002b; Tsujinaka and Mori 2010; Tsujinaka and Yamauchi 2019).

\section{Five Phases of Civil Society in the Postwar Period and General Trends of Association Establishments}

In terms of the associational structure of Japan's civil society, aside from the disconnection between its prewar and postwar formations and the unprecedented rise in the number of associations during the Occupation, Japanese civil society developed steadily up to the mid-1990s. However, Japan's civil society reached a critical turning point in the latter half of the 1990s, exhibiting only marginal increases in the number of associations, stagnating numbers of members and staffs, and rapidly worsening financial conditions. Furthermore, public participation also declined, save for one segment of the advocacy and social service sector. With the enactment of the NPO Law in 1998, systematization in the advocacy and voluntary sector progressed. And the Public-Interest Corporations System reforms (the three related laws were enacted in 2006 followed by the enforcement in 2008) relaxed the government control to the civil society and converted old public interest corporations to new general corporations, accompanying quite a few newly formed groups. Figure 1 illustrates the overall structure and development of civil society in terms of establishments (Tsujinaka and Yamauchi 2019).

Figure 1 uses data from the Establishment Census between 1951 and 2006 and from the Economic Census for 2009 on.

Figure 1 shows the number of associational establishments (offices) where employees are employed (per 100,000 people). This category of political, economic, and cultural organizations does not include the following types of establishments: cooperatives (agriculture, fisheries, forests, small and medium-sized enterprises), establishments for public or semi-public services such as social insurance, social welfare, nursing care, health and medical care, education and learning support, academic research institutes, museums, etc. Included are associations mainly with a membership character rather than a service office character. Political organizations include political parties, supporters, and sects. Economic organizations include trade associations, regional chambers of commerce, and economic and managerial organizations. Culture organizations include academic and cultural societies.

We see a sudden rise in the number of total associations in existence per 100,000 people in 2009 , and this is partially due to the changes in the data that we used. In 2009, a new survey method was introduced to more comprehensively capture associations in this census. This led to some increase in the number of organizations, especially economic and labor associations.

Analysis of the 2016 Economic Census shows that there were 48,753 organizations and almost 264,000 employees in Japan. This means there were 38 organizations and 208 employees per 100,000 people. In terms of the density of organizations, Japan's is higher than that of the United States (32 organizations), and as for the density of employees, Japan's is about three-fourths that of the United States (275 employees).

In examining the association figures in terms of type, while the predominance of business/economic associations (comprising approximately $40 \%$ of the total number of associations) is noteworthy, their ratio remained static throughout the period. In addition, what is particularly striking is the rate of growth in the number of "other" associations ("N.E.C." or "not elsewhere classified" in Fig. 1).

By considering both statistical data and historical consideration as shown in Fig. 1 (Tsujinaka 1988, 2002b), five distinct phases can be seen in the evolution of Japanese civil society.

First phase (1945-1957): During the first half of this period (Tsujinaka 1988), the number of associations sharply increased. In general, rebirth and new formation of civil society took place during this period, with the focal point being labor unions. In the late 1950s, substantial reorganization and retrenchment is evident. 


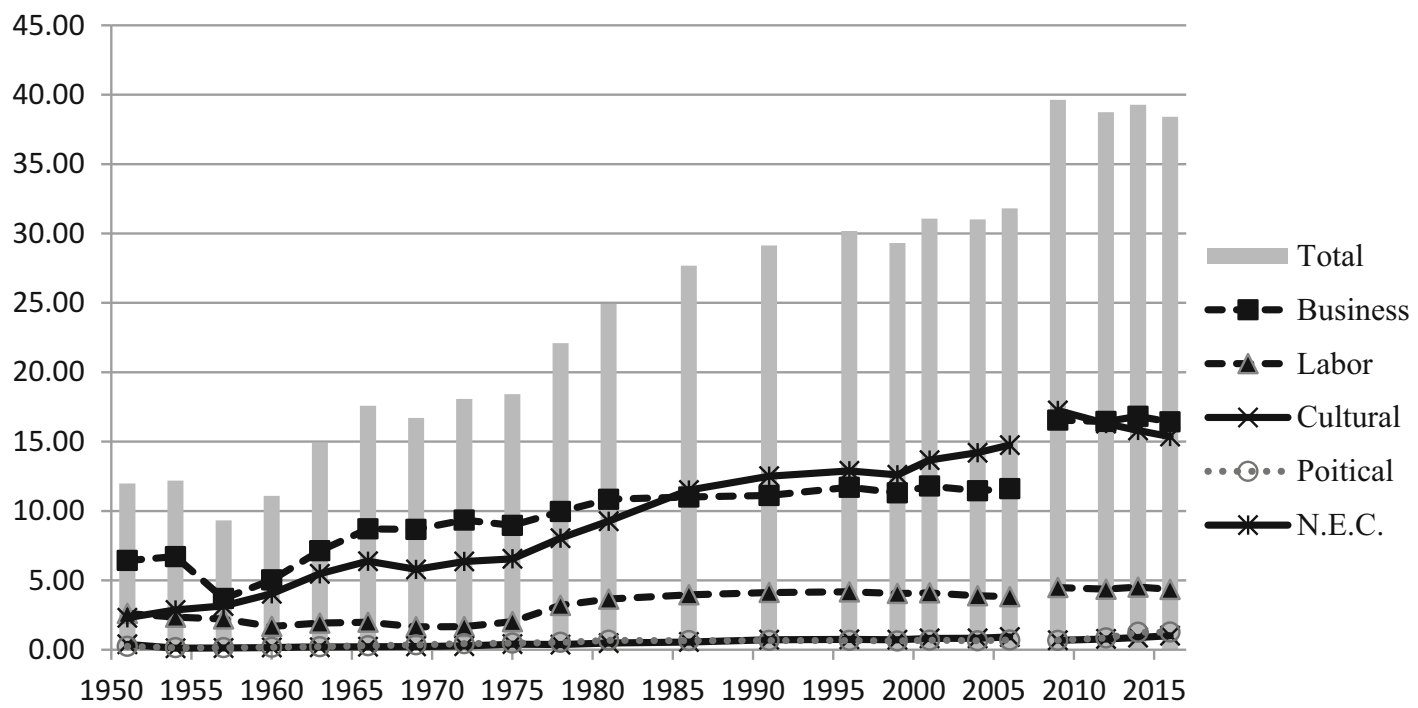

Source: Establishment Census, Economic Census, Statistics Bureau of Japan

Civil Society and Social Capital in Japan, Fig. 1 Number of associational establishments in Japan, 1951-2016 (per 100,000 people). (Note: The bar chart intervals are not even, reflecting the actual survey year)

Second phase (1957-1975): During this phase, there was an overall direction toward developmentalism, business/economic associations and labor unions made up a substantial number of total associational formations, and social movements such as citizens' and residents' movements also started to form. In addition, progressive local governments also went through a reform period. Incidentally, the participation rate continues to increase for all types of civil society organizations.

Third phase (1975-1996): After a critically dangerous period for the ruling government in the 1970s, in the 1980s under the resurgence of the conservative mood, there was a shift from citizens' and residents' movements to citizen participation and activities that coordinated their efforts with the public administration. Awareness of the activities pursued through initiatives led by civil society expanded beyond the local government level to include the central government as well. International NGOs also developed in parallel to Official Development Assistance (ODA) growth in this period. Participation rate for all types of civil society organizations was highest during this phase, especially for neighborhood associations, which reached a $70 \%$ participation rate. On the other hand, the participation rates for economic, agricultural, and labor organizations continued to decline.

Fourth phase (1996-2009): During this period a great number of social service and advocacyoriented NPO associations emerged, in civil society overall, the financial conditions of associations sharply declined, as well as participation figures. At the turn of the century, citizens' sense of participation in neighborhood associations declined dramatically. The same goes for traditional citizen, economic, labor, and agricultural organizations, but to a lesser degree. Overall, the number of those who do not participate increased sharply.

Fifth phase (2009 on): Since 2009, the number of organizations and employees who work at civil society organizations is shown to have increased. In 1996, 37,982 organizations and 236,086 employees were recorded, but in 2016, there were 48,753 organizations and 263,808 employees. In addition to the availability of more comprehensive data from the Economic Census, the significant upsurge between 2006 and 2009 is due to the increase in "other" 
nonprofit organizations, or organizations not elsewhere classified. This sharp increase may also partly be due to the effects of the public interest corporation reforms undertaken in 2006-2008 that scrapped the old system where organizations were subject to the supervision by the competent government agency. Instead, government created a scheme that allows the establishment of general incorporated associations/foundations. As for the citizens' willingness to participate in organizations, the trend continued, though more mildly, toward an increase in the number of those who do not participate. Overall, the participation rate for all organizations has been more or less declining (Tsujinaka and Yamauchi 2019).

\section{"Associational Revolution" and the Formation (Establishment) Year of Civil Society Organizations}

Turning from the government census, the focus now shifts to a set of comprehensive organizational surveys conducted from 1997 to 2017. These surveys named JIGS (Japan Interest Group Survey) have covered Japan (four times, JIGS1 to JIGS4) and four other countries twice, and as of 2018, there is data available for a total of 15 countries. Figure 2 illustrates the findings of the JIGS2 and JIGS4 surveys. JIGS2 survey was conducted in 2006-2007. Figure 2 shows the development of three types of civil society organizations (social association, neighborhood association, and registered NPO) in Japan according to year of establishment.

Here, what is called a "social association" is any group that has a landline telephone and belongs to the union/association classification in the professional telephone directory. It is an organized social entity with a telephone. On the other hand, what we call "neighborhood association" is a group of grassroots inhabitants that exists almost completely in communities ( $98 \%$ of municipalities) without duplication across the country. "NPO," as already mentioned, has recently been institutionalized citizen groups, having a legal status.

Similar data from 15 different countries (Tsujinaka et al. 2007; Tsujinaka and Yamauchi 2019) suggest that an "establishment boom" took place in many countries from the latter half of the 1980s until 2000. In Japan, by contrast, social associations along with neighborhood associations assumed an ascending and enduring pattern of establishment from the postwar period through to the period of high economic growth throughout the 1960s (Tsujinaka 1988). While certainly the noticeable outburst of registered NPOs can be described as an "associational revolution" (Salamon 1994), this did not have much of an effect on the number of association establishments and the number of social associations that were listed in the telephone directory. Basically, the phenomenon of what could be termed an "associational revolution" in Japan only occurred in a few segments of civil society which may be attributable to institutional reform in terms of the 1998 NPO Law and the 2008 revision of the Civil Code. Registered NPOs saw an explosive increase, and a similar phenomenon was seen after 2009 among general incorporated associations and to a lesser extent, general incorporated foundations. Since late 2008, the new public interest corporation reform scrapped the competent authorities system. This resulted in the creation of several thousand organizations free of bureaucratic control. Within several years, the number of such organizations exceeded 50,000 (Ushiro and Sakamoto 2019).

However, it was certain that the establishment boom caused by the legal system reforms happened within some sectors during the 20 years period since the turn of the century. The civil society that Japan now has is different from a previous one in the sense that it enjoys more freedom due to less bureaucratic control.

\section{Present Status of Civil Society in Japan}

Japan's incorporation system (legal personality) in general is complicated, and in addition, particularly with regard to the system for public interest corporations, it has been pointed out that there are a number of regulations and restrictions set forth by the government with respect to civil society (Pekkanen 2006). With or without incorporation, the government's position toward each group within civil society in terms of the attitude it displays with regard to government authorization, 


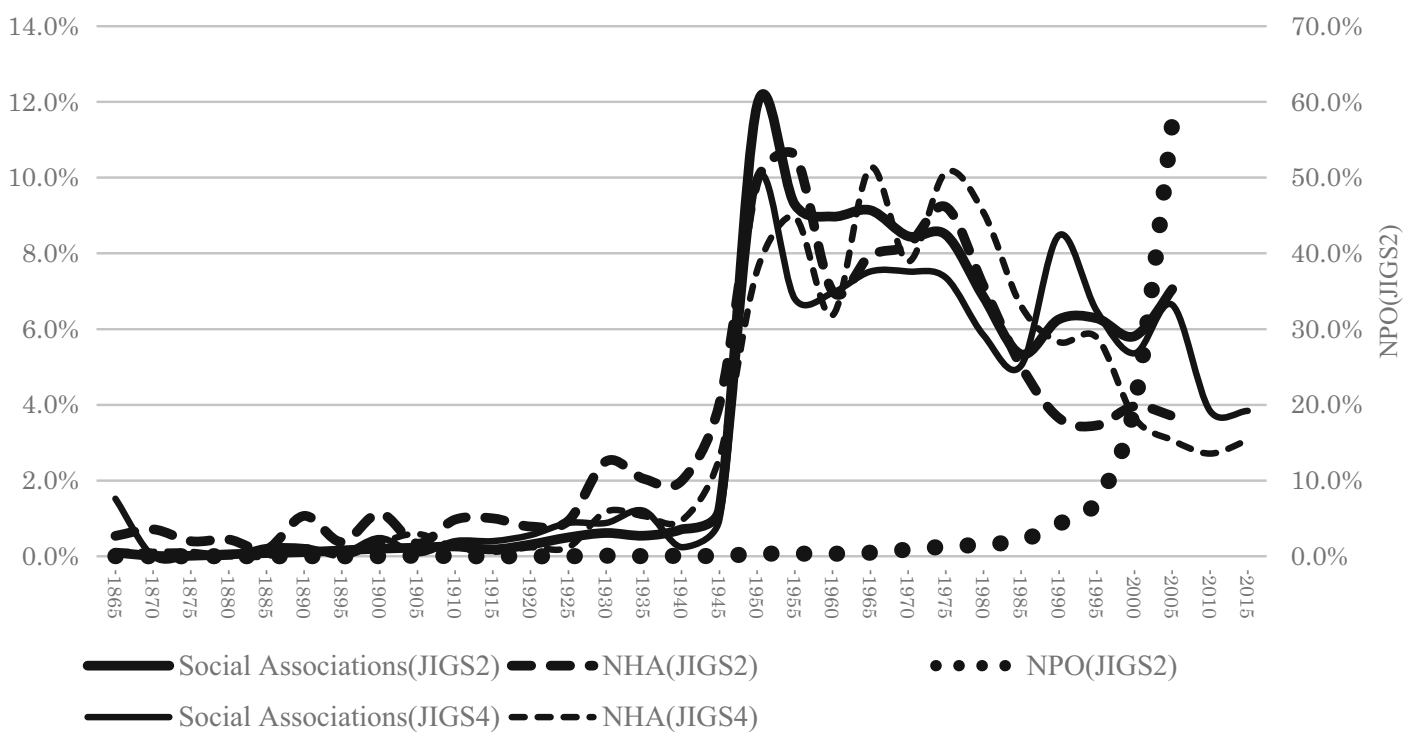

Civil Society and Social Capital in Japan, Fig. 2 Establishment year of Japanese civil society organizations, 1865-2015 (Every 5 years total \% to the whole)

sanctions, and extent of promotion is important (Pekkanen 2006). Even aside from incorporated associations/foundations in the civic code, Japan's corporation system specifies 216 separate categories with special laws for social welfare, education, religion, etc. and allows them to receive benefits such as a prescribed amount of preferential tax treatment. Aside from the public interest corporation, there are 25 separate types of corporations that are relatively close to the government such as semi-governmental corporations, national university corporations, and authorized corporations. With regard to agricultural, fishing, forestry, consumer as well as their medium and small business counterparts, there are over 40 different types of cooperatives.

Throughout Japan, in the period between 2014 and 2017, a total of 440,000 civil society (nonprofit) organizations had corporate status or government registration. For quantitative comparison, in Japan, there are 150,000 national- and local-level public establishments, 2,600,000 business company corporations, 5,600,000 private establishments, 53,000,000 households, and $127,000,000$ people.

Of these, in terms of sheer numbers, religious corporations were the most prevalent with
181,000 , followed by 64,000 registered political organizations, 53,000 medical associations, 52,000 labor union units, 51,000 registered NPOs, 44,000 authorized community-based associations, 40,000 incorporated general associations, 30,000 medium and small business cooperatives, 20,000 social welfare corporations, and 12,000 incorporated general foundations.

It is problematic to accurately capture the groups that have no formal legal status; among the existing 299,000 neighborhood associations, only $15 \%$ possess legal status as authorized community-based associations (in 2013). There are a number of associations such as residents' groups that are connected with recreational activities aimed at senior citizens, housewives, and children and found in the immediate vicinity of neighborhood associations that do not have legal status. Associations in which citizens individually participate with advocacy had found it difficult to acquire legal status before the NPO Law (1998) and general incorporated associationfoundation system was introduced (2008). As a consequence, formalizing their organizations and acquiring amenities for operating an enterprise, such as having a place of activities, staff, and a telephone, had also proved difficult. 
Even if an association has obtained legal corporation status, it is not necessarily the case that they have substance in the actual scope of their activities. For this reason, having a business establishment (office) and a telephone can be said to be only one measure of the structure of civil society.

It is possible to compare data on business establishments in Japan with those of the United States and South Korea. According to the distribution of associations in Japan in 2016, a total of 48,753 associations operate establishments, and of those, $43 \%$ are business/economic associations, $12 \%$ are labor associations, $3 \%$ are political associations, $3 \%$ are academic associations, and $40 \%$ are "other associations." By comparison, in the United States, $16 \%$ are business/economic associations, $14 \%$ are labor associations, $3 \%$ are political associations, $42 \%$ are civic associations, $7 \%$ are professional associations, and the remaining "other associations" are $20 \%$ out of 103,750 establishments in 2014. In South Korea, $19 \%$ are business/economic associations, $8 \%$ are labor associations, $3 \%$ are political associations, $6 \%$ are civic associations, $8 \%$ are professional associations, and the remaining $56 \%$ are "other associations" out of 23,491 establishments in 2016. From this comparison, certain distinct features emerge. Statistically speaking, although it may be difficult to accurately compare these figures as there is neither category in Japan for "civic groups" nor for "professional groups," it is clear that business/economic associations are attached much more significance in Japan (Tsujinaka 2002b, 2003).

In JIGS2 survey, among the four major categories, Japan has the largest proportion of the profitrelated sector (including business and economic associations with direct linkages to producers and markets, labor unions, and agricultural associations), among the 15 countries surveyed. The nonprofit sector is somewhat large, and the citizen group (sector) is the second smallest next to Turkey (China is excluded in this context) (Tsujinaka et al. 2007; Tsujinaka and Mori 2010).

Thus, describing the framework of associations in Japan as assuming the characteristics of the developmental state as originally conceptualized by Chalmers A. Johnson (1982) has its roots in this structural arrangement. However, as the historical phases of expansion show, Japanese civil society in this type of developmental state saw a turning point in the latter half of the 1990s. While the large variation in the number of association establishments shown in Fig. 1 may illustrate nothing more than a static situation, in effect, with the economic stagnation that occurred during the 1990s, the financial conditions of civil society associations, particularly the business/economic and labor associations, suffered a major shock. Comparing figures in 1996 and 2006, on the whole, the financial resources available to associations decreased $30 \%$, deteriorating to the same level as in the mid-1980s. Since then, in order to conduct relief operations after the Great East Japan Earthquake, mainly "other" and "economic" organizations temporarily improved their financial conditions between 2011 and 2013.

\section{Citizen Participation and Social Capital}

The turning point for associations did not stop at the market-oriented associations of the developmental state. As shown in Fig. 3, the subjective attitude of citizen participation in any organization has eroded since the mid-1990s.

The Association for Promoting Fair Elections, an independent public-interest foundation, conducts public opinion surveys during each general election period in which it measures respondents' group participation. Data compiled from 1972 through 2017 provides a comprehensive overview of citizens' attitudes toward participation. The survey asks respondents if they are actually members any of civil society organizations. The highest rates of participation occur in neighborhood associations. While the level of participation in the mid-1980s reached $70 \%$, at the turn of the century, the level of participation has dropped to $50 \%$, further slipping recently to $25 \%$ in the most recent survey (Tsujinaka and Yamauchi 2019).

Incidentally, respondents indicated relatively high rates of participation in groups such as clubs and hobby groups (approximately 14-16\%). Participation in senior citizens' clubs is down from $10 \%$ to around $5 \%$ and participation in women's and youth associations decreased from $10 \%$ level to $4 \%$ in recent years. 


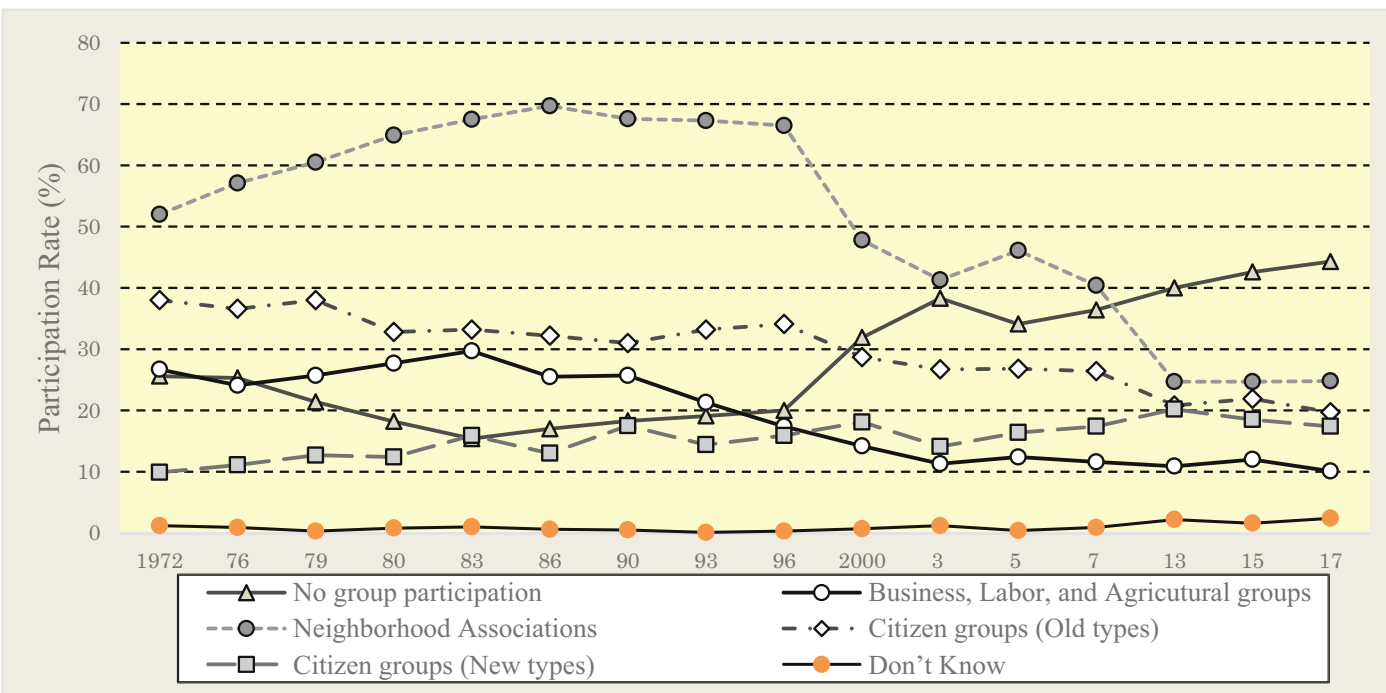

Source: The Association for Promoting Fair Elections, Japan

Civil Society and Social Capital in Japan, Fig. 3 Participation rates and nonparticipation rate

Participation in parent-teacher associations as well decreased by half to $7 \%$. Participation in economic and producer-related associations on the whole declined to around 1-6\%. In general, it is presumed that many associations saw their highest participation figures during the 1980s, except NPO and citizen groups which still record only $2 \%$ level participation. The results also recorded that the 1983 figure of $15 \%$ of respondents who reported "non-participation in any organizations" had grown to over $40 \%$ by the early 2010 s.

Survey results here merely reflect the respondents" "sense" of participation, and thus should be considered separately with the actual number of registered memberships. For example, although the sense of participation in the neighborhood association activities has declined to $25 \%$ in recent years, more than $80 \%$ of the residents in $75 \%$ of the cities actually pay the membership fees and continue association activities (Tsujinaka et al. 2009; Tsujinaka and Yamauchi 2019).

There are not many statistics evidencing the actual number of memberships in civil society organizations, but the membership for consumers' co-operative associations grew steadily until the 2010 s, then remained flat around 60,000,000, which exceeds the number of 53 million Japanese households. Labor union membership hit its highest level in 1994 with 12,700,000, but later declined. After 2005, it remained flat at around $10,000,000$. The unionization ratio hit a record low every year since 1975 , and was $17 \%$ in 2018. Memberships for religious organizations (190,000,000 in 2015, duplicate calculation) and agricultural cooperatives $(4,500,000$ in 2014) are also on the decline.

While there have been debates concerning general feelings of trust and the amount of trust in various systems, comprehending these aspects through qualitative research and various survey outcomes have resulted in large variances (for instance Inoguchi 2002). In fact, trust in itself has a strong bearing in cultural norms and is not readily adaptable to international comparisons. According to the World Values Survey (WVS), the overall trust level of Japan (the percentage of those who responded, "Most can be trusted") remained stable at around 35-40\% between 1981 and 2014 (Ikeda 2019).

Inaba (2014) analyzes Japan's civil society by comparing the results of Japan's first social capital survey conducted in 2003 by the Cabinet Office and his own survey conducted in 2013. The analysis revealed that in Japan, general trust toward 
the public at large is relatively stable (about 25\% and increasing slightly). Nevertheless, day-to-day interaction and structural social capital factors such as participating in organizations declined overall. Specific types of trust such as trust among fellow members also declined overall. On the other hand, citizens participate in local activities (51\% in 2013), sports/hobby activities $(56 \%)$, or volunteer NPO civic activities $(30 \%)$ several times a year. However, in these network/ participation activities, we see some increase in frequency, and the percentage remains at a high level. In the aftermath of the 2011 earthquake, the overall index for network activities seems to be declining in disaster-stricken areas. In nonaffected areas, on the other hand, the participation rate has risen dramatically. Overall, gaps seem to be widening among regions in terms of social capital.

\section{Activities of Civil Society Organizations and Political Influence}

Based on data between 1997 and 2017 drawn from the previously mentioned Japan Interest Groups Survey (JIGS1 to JIGS4), we now look more closely at the attributes and behavior of civil society in Tokyo (Tsujinaka and Togawa 2018).

In 2017, the percentage of organizations that identified themselves as economic (29\%), academic/cultural $(14 \%)$, or civic $(10 \%)$ associations has gone up more than 5 points, as has the percentage of organizations engaged in such activities as providing services to the general public (29\%), organizing awareness programs (36\%), and providing information to nonmembers (26\%). Meanwhile pursuing economic interests $(23 \%)$ has declined by more than 10 points. Overall, funds and staff members have been reduced to small-scale, and their geographical area of activity is shrinking.

The relationship between civil society organizations and central and local government and bureaucracy has become relatively weak. On the other hand, organizations' relationship with political parties and the media has become relatively stronger. Organizations reporting that they contact both political parties and administration have gone down 8 percentage points (16\% in 2017), and those contacting the administration only have gone down 20 points (18\%). Those that contact neither have gone up 20 points $(48 \%)$. On the other hand, requests for consultation by the administration to civil society organizations have increased by more than 20 points (48\%).

In other words, civil society organizations in Tokyo have become smaller in size, and less reliant on the administration. They have shifted their focus to providing services to the broader society. Under financial austerity, the administration and political parties continue to expect a lot from civil society organizations, therefore, the influence of civil society organizations is increasing, although various resources have diminished.

\section{Concluding Assessment}

As a tradition that has extended since premodern times, Japan has a thick layer of voluntary associational activity, with a history of societal relationships that are based on trust. With the Meiji Restoration and the defeat in World War II, while individual structures may have become disconnected, they also passed on a well-developed sense of organization. Since the Meiji Restoration through the postwar growth era, Japan's goals have revolved around modernization stances that have focused on "catching-up" processes. Therefore, Japanese civil society kept the developmentalist structure.

After the war, the concept of civil society was newly adopted as an ideal type. At the same time, a welfare society was created through the employees' welfare-oriented companies and business associations, community service-minded neighborhood associations, and a variety of residential and citizen movements as latecomers.

After the bubble economy burst, the matured civil society in Japan became manifest. The critical years were the mid-1990s, with the temporary loss of power of the conservative government, the major earthquake in 1995, and the enactment of the NPO Law in 1998. With fiscal concerns about aging and with globalization of society, civil society played a major role, and recognition of this fact that overcame various political ideologies 
became clear. There was a burst of NPO activity at the grassroots level, although at the time, there was no fiscal support policy that could accommodate civil society organizations. One particular feature is that on the whole, civil society organizations entered a period of financial uncertainty, same as the government at both national and local levels. In this sense, the associational boom that occurred in the rest of the world in the 1990s also occurred in Japan "partially," only in some sectors and in some regions.

At the turn of the century, government promoted mergers of local municipalities, and through neoliberal public interest corporation reforms, revised the 1896 civil code and abolished the competent agency system in 2008. Fifty thousand general incorporated associations and general incorporated foundations were established within several years after the government regulation was relaxed. This was the biggest boom next to the one that took place after the NPO Law, which also created 50,000 registered NPOs, was enacted. Establishing associations has become relatively easy, as the control of ministries has been relaxed. Civil society has secured freedom at least legally. However, the more recent boom has not reduced the financial instability of associations.

Japan's social capital is quite difficult to measure in a concrete, comparative manner. However, as a whole, social capital, with its perspective in neighborhood associations and NPOs as well as rich developmental associations, can presumably maintain its support. While Japan has not passed through a period of being a welfare state, unlike some of its European counterparts, it continues to aim at a high degree of social service and social capital in the matured civil society, as well as lessening the burden on the government. From this time onward, it can be expected to see new policies and new associations that follow and maintain this path.

\section{Cross-References}

- Associations, Definitions and History of

$\checkmark$ Civic Culture
- Civil Society and Democracy

- Civil Society and Disasters

- Civil Society and Social Capital in Korea

Civil Society, Definitions and Approaches

- Civil Society-Business Relations

- Corporatism

- Nonprofit Organizations

- Putnam, Robert

Reciprocity

- Salamon, Lester

- Social Trust

\section{References}

Alagappa, M. (Ed.). (2004). Civil society and political change in Asia: Expanding and contracting democratic space. Stanford: Stanford University Press.

Aldrich, D. P. (2012). Building resilience: Social capital in post-disaster recovery. Chicago: University of Chicago Press.

Cabinet Office, Japan (Naikakufu-Nippon So-ken). (2003). Social capital: Yutakana Ningen-kankei to Shiminkatsudo no Kou-jyunkan wo motomete (in Japanese). Tokyo, Japan: Nippon Soken.

Fukuda, A. (2006). Kesshu, Kessha no Nihon-shi [A history of association and people in Japan]. Tokyo: Yamakawa-shuppan-sha.

Fukuyama, F. (1995). Trust: The social virtues and the creation of prosperity. New York: Free Press.

Garon, S. (2003). From Meiji to Heisei: The state and civil society in Japan. In F. Schwartz \& S. Pharr (Eds.), The state of civil society in Japan (pp. 42-62). Cambridge: Cambridge University Press.

Ikeda, K. (2019). The reality of contemporary Japanese politics and anxiety over governance (in Japanese). Tokyo: Bokutaskuhsa.

Inaba, Y. (2014). Is the bond broken? Changes from 2003 to 2013 and their implications from three national social capital surveys (in Japanese). Chuo-chosa-ho, Central Research Service, no. 684, 1-4.

Inaba, Y., \& Yoshino, R. (2016). Sosharu Kyapitaru no Sekai [The social capital world]. Kyoto: Minervashobo.

Inoguchi, T. (2002). Broadening the basis of social capital in Japan. In R. D. Putnam (Ed.), Democracies in flux (pp. 359-489). Oxford: Oxford University Press.

Johnson, C. A. (1982). MITI and the Japanese miracle: The growth of industrial policy, 1925-1975. Stanford: Stanford University Press.

Kage, R. (2010). Civic engagement in postwar Japan: The revival of a defeated society. Cambridge: Cambridge University Press.

Miyamoto, K. (1976). Theory of social capital (in Japanese). Tokyo: Yuhikaku. 
Najita, T. (2009). Ordinary economies in Japan: A historical perspective, 1750-1950. Berkeley: University of California Press.

Pekkanen, R. (2003). Molding Japanese civil society: State structured incentives and the patterning of civil society. In F. Schwartz \& S. Pharr (Eds.), The state of civil society in Japan (pp. 175-204). Cambridge: Cambridge University Press.

Pekkanen, R. (2006). Japan's dual civil society: Members without advocates. Stanford: Stanford University Press.

Pempel, T. J., \& Tsunekawa, K. (1979). Corporatism without labor: Then Japanese anomaly. In P. C. Schmitter \& G. Lehmbruch (Eds.), Trends toward corporatist intermediation (pp. 231-270). Beverly Hills: SAGE.

Salamon, L. M., Sokolowski, S. W., et al. (2004). Global civil society: Dimensions of the nonprofit sector. Bloomfield: Kumarian Press.

Schwartz, F., \& Pharr, S. J. (Eds.). (2003). The state of civil society in Japan. Cambridge: Cambridge University Press.

Tsujinaka, Y. (1988). Rieki Shudan [Interest groups in Japan]. Tokyo: Tokyo University Press.

Tsujinaka, Y. (2002a). The cultural dimension in measuring social capital: Perspective from Japan, OECDwebsite, from http://www.oecd.org/dataoecd/2/2/ 2380346.pdf. 31 Jan 2009.

Tsujinaka, Y. (Ed.) (2002b). Gendai nihon no shimin shakai, rieki dantai [Civil society and interest groups in modern Japan]. Tokyo: Bokutakusha.

Tsujinaka, Y., \& Inatsugu, H. (Eds.). (2018). Aftermath: Fukushima and the 3.11 Earthquake (Japanese Society series). Kyoto: Trans Pacific Press.

Tsujinaka, Y., \& Mori, H. (Eds.) (2010). Gendai shakai shudan no seiji kino: Rieki dantai to shimin shakai [Political functions of social organizations in contemporary Japan: Faces of interest group and those of civil society]. Tokyo: Bokutakusha.

Tsujinaka, Y., \& Togawa, K. (2018). Has the environmental change in the 20 years of 21 st century made the Japanese interest group world stagnant? (in Japanese). Tsukuba Journal of Law and Politics, 74, 15-39.

Tsujinaka, Y., \& Yamauchi, N. (Eds.) (2019). Sosharu Kyapitaru to Shimin-shakai-Seiji [Socal capital and politics]. Kyoto: Minerva-shobo.

Tsujinaka, Y., Choe, J.-Y., \& Ohtomo, T. (2007). Exploring the realities of Japanese civil society through comparison. ASIEN, 105, 16-32.

Tsujinaka, Y., Pekkanen, R., \& Yamamoto, H. (2009). Gendai Nihon no Jichikai Chonai kai [Neighborhood Associations and Governance in Japan: Selfgovernance, social capital, social networks and local governance based on the first national survey of thirty thousand associations]. Tokyo: Bokutakusha.

Ushiro, F., \& Sakamoto, H. (Eds.) 2019. Gendai Nihon-no Shimin-shakai (Changing Japan's civil society). Kyoto, Japan: Horitsu-bunka-sha.
Yamaguchi, Y. (2004). Shimin shakai ron: rekishiteki isan to shin tenkai [Civil society: Historical legacy and new developments]. Tokyo: Yuhikaku.

\section{Further Reading}

Gordon, A. (2013). A modern history of Japan: From Tokugawa times to the present (3rd ed.). Oxford: Oxford University Press.

Haddad, M. A. (2007). Politics and volunteering in Japan: A global perspective. Cambridge: Cambridge University Press.

Hamaguchi, E. (1996). Revival of Japanese type trustworthy society (in Japanese). Tokyo: Toyokeizaisinposha.

Ikeda, K. (2006). Political culture and "Social capital": Eastern and western perspectives. In G. Helgesen \& S. R. Thomsen (Eds.), Politics, culture and self: East Asian and North European attitudes (pp. 235-253). Copenhagen: NIAS Press.

Pekkanen, R., Kawato, Y., \& Tsujinaka, Y. (2012). Civil society and the triple disasters: Revealed strengths and weaknesses. In J. Kingston (Ed.), Natural disaster and nuclear crisis in Japan (Nissan Institute/Routledge Japanese studies) (pp. 78-93). Abingdon: Routledge.

Pekkanen, R., Tsujinaka, Y., \& Yamamoto, H. (2014). Neighborhood associations and local governance in Japan. London, UK: Routledge.

Reiman, K. (2003). Building global civil society from outside in? Japanese international development, the state and international norm. In F. Schwartz \& S. Pharr (Eds.), The state of civil society in Japan (pp. 298-315). Cambridge: Cambridge University Press.

Sakamoto, H. (Ed.). (2017). Shimin-shakai-ron (Civil Society studies). Kyoto: Horitsu-bunka-sha.

Salamon, L. M. (1994). The rise of the nonprofit sector. Foreign Affairs, 73(4), 109-122.

The Japan General Social Survey, from http://jgss. daishodai.ac.jp/english/eframe/englishtop.html. 31 Jan 2009.

Tsujinaka, Y. (2003). Japan's civil society organizations in comparative perspective. In F. Schwartz \& S. Pharr (Eds.), The state of civil society in Japan (pp. 129-174). Cambridge: Cambridge University Press.

Tsujinaka, Y., \& Itho, S. (Eds.) (2010). Rokaru Gabananse: Chiho seihu to shiminshakai [Local governance: Local government and civil society]. Tokyo: Bokutakusha.

Tsujinaka, Y., \& Pekkanen, R. (2008). Civil society and interest groups in contemporary Japan. Pacific Affairs, 80(3), 419-437.

Tsujinaka, Y., Choe, J.-Y., Yamamoto, H., Miwa, H., \& Ohtomo, T. (2007). Nihon no shimin shakai kouzou to seiji sanka: Jichikai, shakai dantai, NPO no zentaizou to sono seiji kanyo [The structure of civil society in Japan and political participation: The overall picture of neighborhood associations, social associations, and nonprofit organizations and their political engagement]. Leviathan (Bokutakusha, Japan), 41, 7-44. 
Tsujinaka, Y., Pekkanen, R., \& Yamamoto, H. (2009). Gendai Nihon no Jichikai Chonai kai [Neighborhood associations and governance in Japan: Selfgovernance, social capital, social networks and local governance based on the first national survey of thirty thousand associations]. Tokyo: Bokutakusha.

Tsujinaka, Y., Sakamoto, H., \& Yamamoto, H. (2010). Gendai Nihon no NPO Seiji: Shimin shakai no shin- kyokumen [The politics of non-profit organization in contemporary Japan: A new stage of civil society]. Tokyo: Bokutakusha.

Yamamoto, T. (Ed.). (1998). The nonprofit sector in Japan. Manchester: Manchester University Press.

Yamauchi, N., \& Ibuki, H. (Eds.). (2005). Social capital in Japan (in Japanese). Osaka: School of International Public Policy, Osaka University. 